\title{
EFFectiveness Of Various Supplemental Teaching ApProaches in EdUCATION Of EngineERING MATHEMATICS
}

\author{
Yang Cao \\ School of Engineering \\ University of British Columbia, Okanagan Campus \\ Email: yang.cao@ubc.ca
}

\begin{abstract}
This paper provides information on how two secondyear engineering mathematics courses are delivered at UBC Okanagan. The goal is to provide more diversified teaching and learning strategies that suit students with different learning styles. The list of approaches used in class includes: traditional lectures in classroom; tutorial session and assignments; typed lecture and tutorial notes, Q\&A through Piazza.com; video tutorials through YouTube; Matlab/Maple simulations; and Lecture videos on YouTube. Students can resort to various resources for answers. In order to explore the effectiveness of these approaches, a survey was conducted to collect students' opinions on strength, weakness and improvements of those various assistive approaches. The paper will give a brief introduction of how these supplemental teaching approaches are integrated into the courses, and will discuss the effectiveness of these approaches based on the survey results.
\end{abstract}

Keywords:

Engineering Mathematics, Supplemental Learning, Videos, Software

\section{INTRODUCTION}

Proficiency in mathematics is a fundamental necessity for any successful engineer. However, engineering mathematics has been generally deemed as one of the most difficult courses by students. Surveys show that students are aware of the importance of mathematics in engineering education and career [1]. Gowers provided a philosophical view on why math is importance in general [2].

I teach two 2nd year engineering math courses at UBC Okanagan campus, APSC246 System Dynamics and APSC248 Engineering Analysis III. Topics from these two courses include linear system concepts, mathematical modeling, solving differential equations, vector integrals and multivariable calculus etc. Common concerns from students are (i) the abstractness of topics; (ii) the applicability of those topics; (iii) not getting enough assistance. Klingbeil [3] and Moore [4] explored lab-based and project-based models to enhance students understanding of math concepts. However, their models require additional recourses and funding to implement. As the instructor of a class of 200 students, I need to develop an economical and sustainable teaching and learning resources. The strategies should not only focus on quality of lectures as evidence show that replying only on lectures proves to be not enough in dealing with all the aforementioned concerns. The resources to be developed should give equal or more weight to out-of-class time. The goal is to surround students with necessary tools or resources both in- and out- of classes.

Specifically, I developed a package of supplemental teaching approaches to improve student learning experience. These approaches include social media (YouTube, Piazza), engineering software (Maple/Matlab) and conventional tutorial sessions. Specifically,

- All lecture notes are typed and self-contained. Concepts are explained in simple language.

- Videos were created targeting at common challenges experienced by many students in assignments and lectures. Videos were uploaded to YouTube for ease of access.

- Tablet is used for lecturing and all lectures are recorded and uploaded to YouTube.

- Piazza.com was used as a venue of Questions and Answers.

- Maltab and Maple are commonly used engineering software in visualization and computing.

- Tradition tutorial sessions are still kept as an integral part of the courses.

Section 2 provides details on how these assistive teaching approaches were integrated into the curriculum. 


\section{SUPPLEMENTAL TEACHING AND LEARNING APPROACHES}

Over the years of teaching, I have developed a combination of in- and outside class approaches to bring math alive and to have enough online resources available for students to self-serve and get assistance.

\subsection{Bring Math Alive and Relate to Real-life Examples}

In the lectures, I try to better explain the mathematical concepts and theories. How to better deliver or explain abstract mathematical topics is an art and requires ample research and preparations. Visualization is one important step to make formula alive. I developed a number of Maltab and Maple programs to visualize typical concepts in lines, planes, surfaces, gradient vectors, directional derivatives, Lagrange Multiplier, system response, vibrations, and Fourier series etc. Assignment questions were given for students practice based on sample programs. For example, when teach multivariable functions, I asked students to plot using following implicit function

$$
\left(x^{2}+\frac{9}{4} y^{2}+z^{2}-1\right)^{3}-x^{2} z^{3}-\frac{9}{80} y^{2} z^{3}=0
$$

When students realize that it is actually a heart-shaped surface as shown in Fig. 1, one can see an immediate affection towards that topic. Interestingly, many students actually used the plot as a surprise on Valentine day.

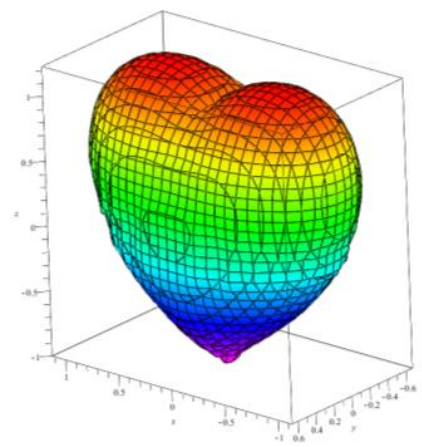

Fig. 1. Heart-shaped surface

In APSC246 (System dynamics), one topic that often plagues students is "convolution". At early age of teaching, I spent so much time including additional tutorials to explain. Recently, I developed a Matlab animation to demonstrate the graphical approach in solving convolution questions. A video is made and posted (https://youtu.be/jwlfSIBNqP8). Typed notes together with this animation saved so much traffic to my office.

I was often asked by students that where do we use this theory or why do we learn this concept? It doesn't help much by simply telling them vector calculus is essential in electromagnetism or fluid mechanics, or differential equation is the fundamental for control system design. It is better to use understandable reallife examples to get better understanding. I strive to use simple languages to explain the dry math. For example, when teaching surface integral, I used the Cartoon "Cloudy with a Chance of Meatballs". One can imagine the falling meat balls as the vector field. If you are going to catch meat balls using a bowl (flux), how much can be caught depends on the falling speed (velocity of the vector field) and the orientation of the bowl (surface) and the falling meat balls. This is nicely connected to the surface integral formula.

$$
\text { flux }=\iint_{S} \vec{F} \cdot \hat{n} d A
$$

\subsection{Develop On-line Learning Materials and Q\&As}

Another typical feedback from students is that they are not getting enough assistance or attention from professor. This is particularly true when one has to deal with large classes. Weekly lectures and tutorials do not provide adequate interactions with students. Student would be more interested in the subject if he feels the closeness of the instructor to him.

In 2010 winter term, I started to provide video tutorials on selected topics such as impulse response, system causality, convolution, and system modeling. Based on commonly asked questions from assignments, I recorded videos on selected questions to give some hints. There were about 30 videos created. This experiment turned out to be so well received. Many students commented on how helpful and convenient these videos were. This gives me great confidence and encouragement to expand the library of the contents of videos. In 2013 winter terms, I started to record my lectures and posted on YouTube. As of now, I have a full list of videos for all my lectures in APSC248 and APSC246. The videos did not draw students away from lectures. Quite opposite, knowing that lecture time is not the only opportunity to learn, students would not panic if they get stuck on a concept in class. They can always resort to the videos which give students access to lecture contents and most importantly, access to my lecturing anytime and anywhere. For my effort, I was voted by $2^{\text {nd }}$-year student for professor in "pioneering in teaching for excellence" award 6 years in a row.

Arguably, there are bountiful of resources including videos on a variety of engineering mathematical topics. Students could be directed to those resources. However, I feel that teaching is like running a business. It needs to have its own proprietary characteristics. It needs to bear the signature of the instructor who is directly responsible for the class. Like a piece of blank paper, 
students look up to the instructor for guidelines and expectations to produce a beautiful work. Instructor is the master of the domain of his class. Thus the videos are produced specifically targeting common problems within certain cohort. This way, the videos work more efficient and effective.

Ease of access and flexibility of locating where to review are another few advantages of using videos. Class time is fast paced. It is not easy to maintain constant focus during a typical 50-90 minutes lecture. Research shows a waxing-and-waning pattern of attention span, varying among 4, 8 and 10 minutes [5]. At same time, it is inevitable to get stuck at some point as first-time learner. Active learning technique is one solution. However, no pedagogy applies to all students. I strongly believe that self-led learning style if the ultimate solution. After class, students know what they are lack of. Using the lecture videos, they can manage their own schedule and learning styles efficiently. Imagine that students are watching the video 9 o'clock at night with their pajamas on, a cup of tea and taking break at their own comfortable pace.

Up to today, I have 232 teaching related videos on my YouTube Channel (channel name: UBCOAPSC246) and over 150, 000 views. The videos are not only helping my own students, due to the popularity of YouTube, they are also making an impact to numerous viewers around the world.

To put students in the center of this learning package, there is one more piece of puzzle missing. That is how to answer student questions in more timely fashion. Piazza.com provides a free and easy to use platform for students to ask and answer questions. It's Wiki-style Q\&A makes finding the answer easy. One can use TEX to type mathematical expressions producing elegant Q\&As. A snapshot using Piazza.com in vector calculus courses is given in Fig.2.

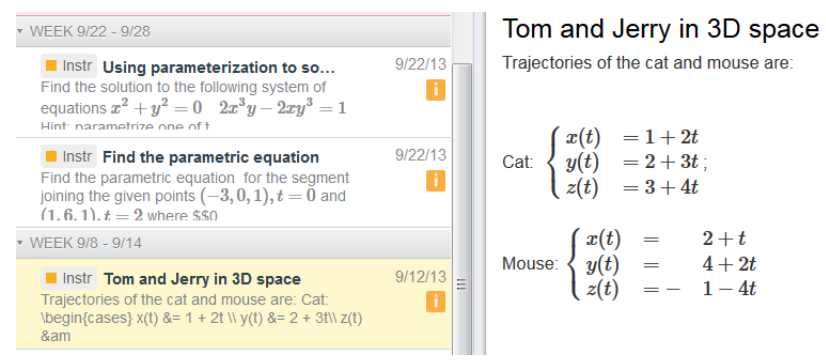

Fig. 2. Snapshot of using Piazza.com in APSC248.

By using this platform, Q\&A is not limited to office time and instructor anymore. Student can answer their peer questions. This actually provides more synergy in student interaction. When new question is raised, an email is sent to instructor. The question could be answered in time.
To summary, this student-centered supplemental learning package gives students flexibility of accessing resources of what they want and when they want, according to individual level of learning and style of learning. With is set of solutions, students feel the presence of instructor and get assistance from instructor and possibly their peers.

\section{SURVEY ON EFFECTIVENESS OF VARIOUS ASSISTIVE TOOLS}

In order to explore the effectiveness of these supplemental learning approaches, a survey was conducted to collect students' opinions on strength, weakness and improvements. A short survey containing 3 multiple choices and 2 questions was posted on WebCT by UBC Okanagan Center for Teaching and Learning. Students will spend no more than 5 minutes to finish the survey. Survey results were collected at the end of the term.

Part I of the survey is given in Fig. 3. Part II of the survey requires students to provide comments:

- Considering your learning style, which approach should be given more preference in the future: YouTube video, Piazza, Maple/Matlab, or weekly tutorials?

- What other assistive approaches would you recommend for learning engineering mathematics?

Total respondents are 39 students. The low number of respondents is mainly due to the timing of the survey which was close to the end of term. However, results are representative.

\begin{tabular}{|c|c|c|c|c|c|c|}
\hline \multicolumn{7}{|c|}{ The use of YouTube enhanced my ability to learn the material: } \\
\hline O & \multicolumn{2}{|c|}{ O } & O & O & O & ○ \\
\hline $\begin{array}{l}\text { Strongly agree } \\
\text { If you agree, e }\end{array}$ & $\begin{array}{r}\text { Agr } \\
\text { xplain ho }\end{array}$ & w. If you don & $\begin{array}{l}\text { tral } \\
\text { agree, exp }\end{array}$ & $\begin{array}{l}\text { Disagree } \\
\text { ain why. }\end{array}$ & $\begin{array}{l}\text { Strongly } \\
\text { disagree }\end{array}$ & $\mathrm{N} / \mathrm{A}$ \\
\hline \multicolumn{7}{|c|}{$\begin{array}{l}\text { The use of Piazza provides a solution of getting prompt answers to my questions either from } \\
\text { my instructor or classmates: }\end{array}$} \\
\hline 0 & ○ & O & 0 & 0 & 0 & \\
\hline Strongly agree & Agree & Neutral & Disagree & $\begin{array}{l}\text { Strongly } \\
\text { disagree }\end{array}$ & N/A & \\
\hline \multicolumn{7}{|c|}{ The use of Maple software gives me insight of what is behind a mathematical expression: } \\
\hline O & ○ & O & ० & ○ & 0 & \\
\hline Strongly agree & Agree & Neutral & Disagree & $\begin{array}{l}\text { Strongly } \\
\text { disagree }\end{array}$ & $N / A$ & \\
\hline
\end{tabular}

Fig. 3. Part I of the survey: General information

Results for part I of the survey are presented in Fig. 4. Based on results in Fig. 4, it is obviously that Videos are overwhelming welcomed by students. Videos play an important part of role in assisting student learning outside classroom. 


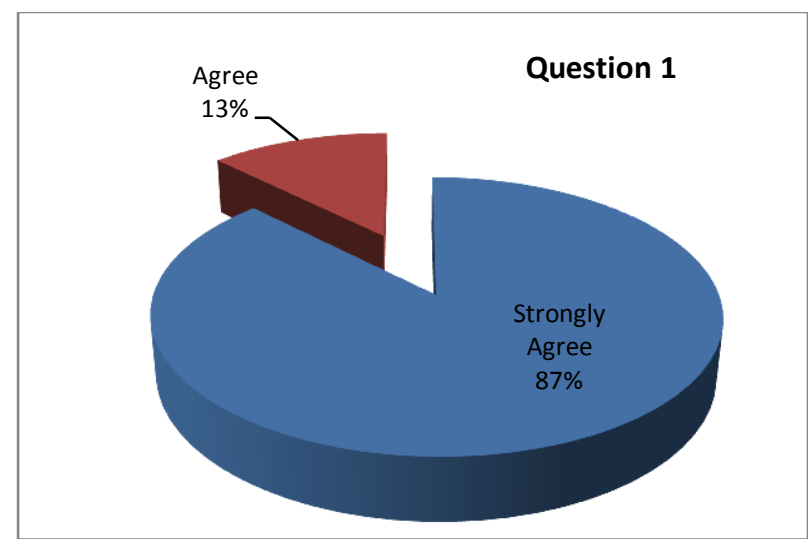

Question 1: The use of YouTube enhanced my ability to learn the material

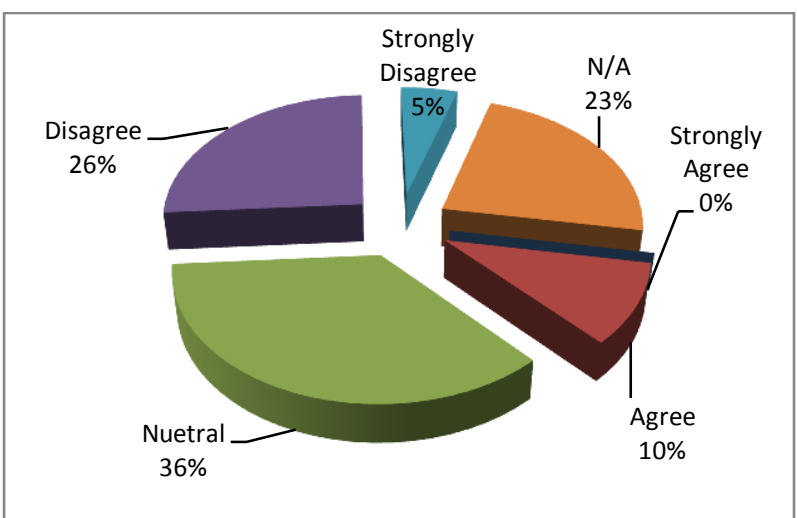

Question 2: The use of Piazza provides a solution of getting prompt answers to my questions either from my instructor or classmates

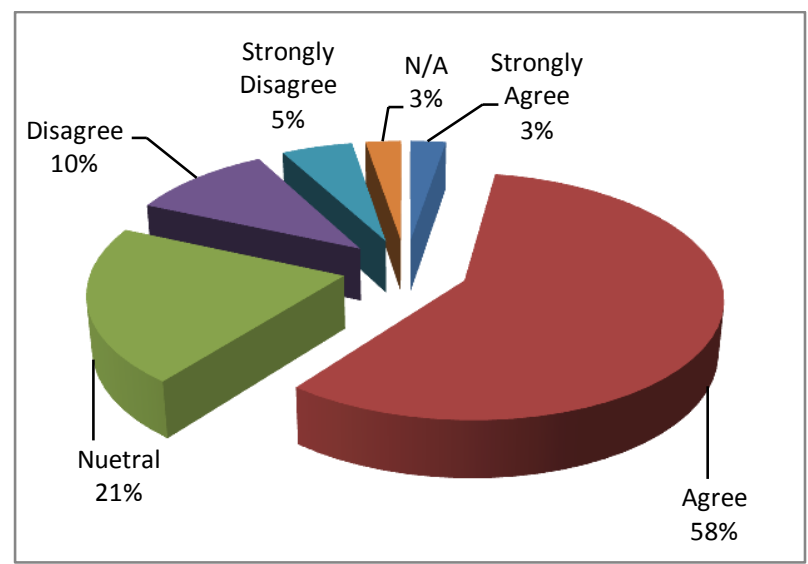

Question 3: The use of Matlab/Maple software gives me insight of what is behind a mathematical expression

Fig. 4. Results of part I of the survey

There are mixed feelings about the usage of Piazza.com in Q\&A. There is a learning curve in how to use Piazza, especially using TEX for entering math expressions. The objective is to get students involved and encourage students asking questions. As an instructor, properly using the forum could potentially increase student participation in Q\&A. I plan to attract student interest to use Piazza more often by posting more questions and examples on the forum.

Similar issue can be observed on the usage of Matlab/Maple. Both software are powerful and need some time to grasp it. I plan to provide video tutorials to demonstrate how to use the software to speed up the learning curve.

For the first comments requested in the part II of the survey, video tutorials and weekly tutorials are the winner. Majority of the respondents would like to see an expansion of the topics in video tutorials. The weekly traditional tutorial is still one of student favors as it provides face-to-face learning experience which can be seen from following excerption:

"weekly tutorials, specifically cause there is a person or instructor there that can answer questions if any arise immediately, where the other methods don't have that luxury".

For the second comments requested in the part II of the survey, a list of suggested additional assistive tools is compiled below:

- Supplemental Learning sessions from University

- Lecture notes, tutorial notes or videos before lectures

- More visual demonstrations (better integration of Maple into lecture materials)

Supplemental learning session is a service ran by university. It is currently only offered to first year students. The suggestion was passed to University administrative.

For the second suggestions, as one student suggested, I quote:

"Some prof's require certain chapters to be read prior to class lectures so that they are able to cover more in a lecture and from a more in-depth approach. I would suggest posting a lecture of calculus or system dynamics or what have you on YouTube ahead of time. The class can watch this video at home, while eating pizza and popcorn, take whatever notes they like, and then come to class prepared with in-depth questions and a good understanding of the topic matter. Consider it, reading ahead in the digital age. (of course some students won't bother coming to class, but let the slackers slack off, it's their future)"

It is in-line with the pedagogy of flipped-classroom. Since all lecture videos are ready, it is feasible to try it out and I am considering in experimenting this approach in the coming year. 


\section{CONCLUSIONS}

Teaching is no longer defined as simply delivering lectures. Student feedbacks show a need for connection and interaction. Various supplemental teaching approaches were used outside of class to help students understand the engineering mathematical concepts and overcome the challenges. Student learning experience is greatly improved with the supplement of assistive approaches. However, assistive approaches are to work with lectures, not to substitute the lectures. As said by Tony Bates, "Good teaching may overcome a poor choice of technology but technology will never save bad teaching".

\section{Acknowledgements}

Ethical approval was given for the survey by UBC Behavioral Research Ethics Board with certificate number C10-03088-A001.

\section{REFERENCES}

[1] Mary Coupland, Anne Gardner and Georgina Carmody, "Mathematics for Engineering Education: What Students Say", Proceedings of the 31st Annual Conference of the Mathematics Education Research Group of Australasia, pp.139-146, 2008.

[2] W. T. Gowers, "The Importance of Mathematics", https://www.dpmms.cam.ac.uk/ wtg10/importance.pdf.

[3] Nathan W. Klingbeil, Richard Mercer, Kuldip S. Rattan, Michael L. Raymer, and David B. Reynolds. "Redefining Engineering Mathematics Education at Wright State University" ASEE Annual Conference Proceedings. Jun. 2006.

[4] Hassan Moore, "Using projects in mathematics and engineering mathematics courses designed to stimulate learning", $120^{\text {th }}$ ASEE Annual Conference Proceedings, Jun. 2013.

[5] Bunce, D. M., Flens, E A., and Neiles, K. Y., "How long can students pay attention in class? A study of student attention decline using clickers", Journal of Chemical Education, 87, 1438-1443, 2010. 